\title{
Comunicação, globalização e nova ordem mundial*
}

\author{
Maria Auxiliadora Andrade de Echegaray $* *$ \\ Jorge Cardoso Castro $* * *$
}

\section{Resumo}

A Globalização é analisada em algumas de suas diversas interfaces, dando-se especial ênfase às suas relações com a mídia. São discutidas algumas macrotendências contemporâneas do comunicativo na Europa, particularmente na Espanha, e na América Latina, com destaque para o Brasil. Busca-se, através de um estudo comparativo, apontar os novos desafios impostos à pesquisa da comunicação no contexto do modelo neoliberal.

Palarras-chave: globalização; identidades; tecnificação da sociedade; novos discursos midiáticos; receptores; imaginário social.

Harry Pross escrevia, acertadamente, que cultura e comunicação são inseparáveis, acrescentando que na comunicação trata-se sempre de uma questão de poder.

Cultura e comunicação são duas coisas inseparáveis, já que a cultura se constitui de comunicações repetidas. Como, quando, onde e o quê comunicamos é o que nos converte em objetos culturais. $\mathrm{O}$

\footnotetext{
* Trabalho apresentado ao V Encontro Iberoamericano de Ciências da Comunicação (IBI:RCOM) - Porto (Portugal). 19-21 nov. de 1998.

** Bibliotecária. mestre em IIistória. especialista em Metodologia do Ensino Superior. prolessora do Curso de Biblioteconomia. Diretora da Faculdade de Comunicação e Biblioteconomia da Universidade Federal de Goiás - UFG. membro da INTERCOM e da Associação Nacional de Pesquisadores em Ciência da Informação e Biblioteconomia - ANCIB. Pertence ao Conselho Editorial desta Revista e é membro consultivo da Secretaria de Ciência e Tecnologia do Estado de Goiás. nas áreas de Tecnologias Apropriadas e Difusào Tecnológica. E-mail: cizinha a zaz.com.br e cizinha a facomb.ufg.br

$* * *$ Jornalista. doutor em Comunicação Social. licenciado em Geografĩa e História. estudos de Sociologia. "master" especialista em Técnicas de Investigação qualitativas e quantitativas-estatísticas. "master" especialista em Sociologia do Consumo e Investigações de Mercado. professor da Universidade Internacional Sek da Espanha. coordenador da revista de divulgação espanhola "Quo" de Hachette Filippatti e membro do Conselho Editorial desta Revista.
} 
recurso repetido em determinadas comunicações é o que decide sobre a cultura e sua mudança (...) A história política diz que os impérios duram o que dura sua hegemonia sobre os meios de produção de comunicação (Pross, 1987).

O país que possui hegemonia sobre os meios de produção de comunicação possui, também. a hegemonia política e militar o que, via de regra, costuma coincidir com a posse da hegemonia econômica.

Concordamos plenamente com este postulado e o testemunho da sua veracidade é o próprio exemplo da história mais recente: o domínio político, econômico e cultural dos Estados Unidos, desde o fïm da Segunda Guerra Mundial. Até aí, nada de novo.

Se fizermos agora um viés para falar um pouco da questão da informação, no contexto da "Sociedade da Informação" (ou do Conhecimento), podemos afirmar, com autores como Fiske' citado por Orozco Gomez ${ }^{2}$, que a informação converteu-se não apenas em um referencial para a ação, para a tomada de decisões, mas em suporte do conhecimento ou dos conhecimentos. A informação é qualificada aqui como um "instrumento modificador da consciência do homem e de seu grupo social. (...) Se nenhuma alteração ocorrer não aconteceu a assimilação da informação". isto é, não se efetivou a relação "informação-conhecimento" (Barreto. 1998). É importante enfatizar que o acesso aos conhecimentos, sua posse e circulação nas sociedades contemporâneas contém no seu âmago, como nunca antes, poder. É claro que se trata de poder de uns poucos: é um poder. cada vez mais. excludente. Tudo isto significa que o caminho até o bloco de poder está delimitado. entre outras coisas. pela capacidade de passar de ser excluídos (pessoas ou nações) para possuidores do passwrord. do acesso à informação, sua fontes e seus meios de circulação. Ainda para outros teóricos como Giroux ${ }^{3}$. citado por Orozco Gomez ${ }^{4}$ a drástica divisão entre os que têm e os que não têm. depende. em grande parte. de suas possibilidades de definir o desenvolvimento dos meios, de ser sujeitos da informação circulante. de gerar os discursos midiáticos e. definitivamente. de ter a possibilidade de construir e re-criar a representação de si mesmos e do que acontece no mundo.

As sociedades atuais, em especial os segmentos letrados (é bom enfatizar que na América Latina. particularmente no Brasil. o índice de analfabetismo é alarmante. atingindo 17\%. em 1997). mobilizam-se

Comun. Inf., v.1, n. 2. p. 283-300, jul./dez. 1998 
diante de duas questões complexas e polêmicas: a crise de paradigmas e a globalização da economia (ou do capital, mais propriamente). $\mathrm{O}$ primeiro fenômeno afeta os procedimentos científicos, notadamente o comportamento da Academia: o segundo, as relações de produção e de trabalho. a qualidade de vida no planeta.

Nos últimos anos, sobretudo a partir da derrocada da União Soviética e da queda do muro de Berlim, só se fala em "globalização" e na "nova ordem mundial". ou seja, no processo de globalização da economia e sua liderança pelos Estados Unidos da América. Contudo. embora os meios de comunicação de massa do mundo inteiro procurem difundir este discurso entre a opinião pública, pouco têm dito sobre o verdadeiro alcance do seu significado. que não é outro senão a submissão sutil do planeta às diretrizes emanadas de Washington ou das centrais e sucursais das principais multinacionais que operam em escala mundial.

De fato, o controle planetário por um número pequeno de transnacionais, que surgiram como conseqüência do processo de concentração industrial e financeira não é um fenômeno novo. O que agora lhe dá uma dimensão diferente. é o fato de que o grande capital internacional pode atuar com liberdade e sem entraves em praticamente todo o mundo. sem que nenhum muro de contenção o impeça. A derrota do socialismo no Leste Europeu e, com ele, a perda do referencial marxista para milhões de trabalhadores, não só do Terceiro Mundo e países emergentes, como também para os trabalhadores do Primeiro Mundo, favorecem qualquer justificativa moral da filosofia utilitarista que sustenta o império do mercado.

Desde a década de 1960, as primeiras nações industrializadas tinham dado grandes passos para a concentração industrial, a centralização do capital e, portanto, para a expansão transnacional. A concentração em escala nacional e mundial tem estado inserida nesse processo. $\mathrm{O}$ resultado foi que surgiu um sistema econômico mundial que está controlado pela centralização do capital, da tecnologia e dos sistemas de produção e distribuição. Este sistema de oligopólio molda e mantém as estruturas de produção internacional, do marketing e do consumo. No coração do sistema estão as empresas transnacionais (Hamelink (1981).

O próprio Mattelart (1991) documentou a existência de um imperialismo da comunicação como parte de um esquema mundial do

Comun. Inf., v.I. n. 2, p. 283-300, jul./de=. 1998 


\title{
286
}

imperialismo político-econômico. Com relação à dinâmica do capitalismo no contexto da nova ordem mundial, a reflexão do sociólogo e economista alemão Dieterich (1991) é reveladora:

\begin{abstract}
Hoje, esta lei de comportamento do homo homini lupus é mais visivel que nunca. Enquanto o Capitalismo tem afundado $85 \%$ da espécie humana na miséria, bem grande tem sido a cegueira para negar esta verdade. O estado do mundo atual não só manifesta ausência de um mecanismo antropológico-ético natural, ou seja, genético ou hormonal, no homo supiens, senão também fracasso dos seus remédios sociais e políticos. O direito internacional, que no nível da espécie deveria ser o bastião mais forte para conseguir uma convivência democrática e igualitária entre os membros da humanidade, converte-se em trapaça diante dos interesses dos poderosos. Os grandes tubarões do sistema internacional comem as sardinhas com impunidade. chamem-se estas sardinhas nicaragüenses, cubanos ou palestinos.
\end{abstract}

O economista e cientista político Henrique Rattner ${ }^{6}$ define a globalização, cuja origem ele atribui à primeira metade deste século. como uma evolução do capitalismo, mas que traz dentro de si contradições, apresentando aspectos positivos e negativos. Trata-se de uma versão melhorada do mercantilismo. que divide o mundo num grande mercado, com a diferença de que no mercantilismo o papel dos Estados Nacionais era de suma importância. enquanto na sua versão atual ele ficou, cada vez mais, reduzido. O Estado sofre uma crise de identidade ao perder parte de seu poder de controlar as relações econômicas entre os países. O mundo, agora submetido à essa nova ordem, passa a ser controlado por conglomerados transnacionais, acima dos estados de direito, com regras próprias, ultrapassando barreiras de língua, cultura, religião e causando uma internacionalização da riqueza e também da miséria. Há ricos e miseráveis em todos os países do mundo, independentemente de quão ricas sejam suas empresas transnacionais.

Nos países ditos emergentes ou de "industrialização tardia". como é o caso do Brasil. os efeitos nocivos da globalização são mais ostensivos: a legislação branda em relação ao meio ambiente e aos direitos trabalhistas; incentivos fiscais excessivos, favorecendo as grandes corporações; fragmentação do espaço político e social: déficit público crônico, contido muitas vezes por cortes na área social: a usurpação

Comun. Inf., 1.1, n. 2, p. 283-300, jul./de=. 1998 
do Estado pelas grandes empresas. que assumem o papel de motor do desenvolvimento econômico: desemprego e miséria. causando reação na sociedade civil (o movimento sem-terra no Brasil. por exemplo). entre outros.

Por outro lado. a queda das fronteiras para o capital, que acabou por impulsionar os novos sistemas de telecomunicações por satélite, a microeletrônica e as noras tecnologias de processamento de informaçòes. sào apontadas por este autor. como um ponto positivo do processo de globalização. I loje. qualquer pessoa tem acesso a um número cada rè maior de informações e pode se comunicar. em tempo real. sem sair de casa. com o mundo inteiro. via Internet. A questão que se impõe. neste momento. é saber qual a contribuição destas infovias. ou auto-estradas da informação, para a cidadania. ou seja, qual a participação de tais avanços tecnológicos no processo de emancipação do homem?

Se usarmos aqui como referência as categorias espaço e tempo (o "aqui-agora"), ao invés das auto-estradas da informação, por exemplo, para discutir a possibilidade de re-conquista dessa emancipação, numa sociedade globalizada, podemos, metaforicamente, dizer que o homem moderno vive num tempo e num espaço virtuais. O seu espaço/tempo social-histórico é, portanto, virtual. Será virtual, também. a sua liberdade? O conhecido lingüista Chomsky (1998). numa recente entrevista para o jornal espanhol El País, fez a seguinte afirmação:

Enquanto os jovens se dependuram na Internet estão participando de mundos imaginários, onde se relacionam com gente imaginária. Internet é [um meio] perigoso, especialmente para adolescentes, porque cria a ilusão de que estão em contato com a gente. Mas, na realidade, estão completamente isolados. Os adolescentes têm mais contato com pessoas virtuais do que com pessoas reais e isso é um risco muito grave.

O "estar junto", mesclar-se, dividir idéias e pensamentos, conhecer novas visões de mundo, ou cosmovisões. perceber o "outro" ou estar "diante do outro". dispunham o homem para a vida coletiva, para a consciência de povo, de nação, para o fortalecimento de uma expressão cultural. O diálogo virtual impede essa experiência, "economiza" as relações afetivas verdadeiras e, às vezes, compromete a saúde emocional dos internautas. 
Parafraseando Lyotard (1996), poderíamos perguntar, ainda?

Será verdade que nesta crise, que diz respeito às condições do espaço e do tempo (com suas duas expressões, moderna: nada mais resta senão o espaço e o tempo, e pós-moderna: não nos resta nem mesmo o espaço e o tempo), será que neste trabalho, que abordamos sob o ponto de vista da comunicação, há simplesmente a perda de alguma coisa (a doação ou a apresentação) sem que haja ganho qualquer?

Neste caso, "perdemos a terra (Husserl)". conclui o autor. isto é. o aqui-agora, mas será que ganhamos alguma coisa. e de que forma ganhamos?

É importante lembrar também a emergência de questões e pensamentos sobre as novas tecnologias - entre as quais destacamos as tecnologias da imagem, inclusive a imagem multimídia - que pontuam as sociedades modernas, no nível dos diferentes saberes: míticos. fỉlosóficos, artísticos e científicos. Segundo Parente (1996, p.7), a diversidade de pontos de vista perceptível na leitura dos ensaios, escritos por filósofos, físicos, matemáticos, semiólogos, sociólogos, artistas plásticos, videomakers, enfim, por teóricos e especialistas de múltiplas disciplinas - algumas delas nascentes, como a infografia - e publicados no livro Imagem - máquina: a era das tecnologias do virtual, é esclarecedora. Tal diversidade nos leva. diz ele, inevitavelmente, a uma "compreensão transdisciplinar do poder da imagem na modelização do mundo e do sujeito da contemporaneidade, numa dimensão indissociavelmente ontológica e prática“. Discutir essa relação imagemmáquina, no interior do processo de globalização, é algo que deve interessar à ideologia comunicacional.

Agora, um pequeno viés no campo da política para analisarmos alguns dos abalos produzidos pela globalização nos regimes democráticos. em especial nos países subdesenvolvidos. situados na periferia do sistema mundial. Martins (1996). com base em estudos realizados por Eric J. Hobsbawn. François Chesnais. Robert Kurz. Luiz Gonzaga Beluzzo. José Carlos Braga e Perry Anderson. lembra que entre os malefỉcios da globalização.

encontra-se a destruição das condições que tornam possivel a construção e o funcionamento do regime democrático. Resultado:

Comun. Inf.. 1:1. n. 2. p. 283-300, jul. dez. 1998 
somos tangidos pela globalização e nada podemos fazer contra seus aspectos negativos, na medida que não dispomos dos instrumentos de luta que só o regime democrático poderia nos proporcionar.

Podemos falar. pois. de uma nova ordem mundial. Do ponto de vista político e estratégico. o fim da bipolaridade levou a um mundo unipolar governado pelos Estados Unidos. que ao manter suas posições militares. também mantêm seu domínio cultural e comunicativo. Já sob uma perspectiva puramente econômica, o que se nos apresenta é um mundo multipolar. no qual sobressai um eixo horizontal Oeste-Leste no hemisfério Norte formado pelos Estados Unidos. Canadá, União Européia e Japão, em acirrada competência pelo controle dos mercados emergentes da América Latina - em especial do Brasil - e das matérias primas dos estados do Terceiro Mundo. Desse eixo sairá. sem dúvida. no século XXI, um ganhador. que bem poderia ser a Europa. em função do hipotético e complicado sucesso que possa ter a sua união política e econômica. Esta seria a tese do economista norte-americano Lester Thurow. Dai os grandes investimentos da Europa e. mais particularmente. da Espanha, nos países da América Latina: a penetração de bancos espanhóis no Brasil, o controle da telefonia móvel neste país por empresas espanholas, a tentativa de controle do setor elétrico, turístico etc.

Trata-se de um ótimo plano estratégico da Espanha para ter acesso a mercados internacionais e compensar. assim. a perda de investimentos do restante dos países europeus. que com certeza terão lugar nos próximos anos. como conseqüência da abertura de novos mercados no Leste Europeu. onde países como a Alemanha têm grandes interesses. A questão nuclear é saber como pode a América Latina defender-se dos especuladores norte-americanos e, agora, desse novo desembarque europeu? Uma alternativa talvez fosse a busca de uma integração regional latino-americana.

Para Martín Barbero ${ }^{7}$, o cenário da integração regional latinoamericana é mais bem compreendido quando colocado em contraste com o europeu. Mesmo considerando que os dois processos de integração seguem os caminhos traçados pela globalização, as contradições que mobilizam são bem diferentes. Na União Européia. em que pese a grande diversidade de línguas e de história que divide esses países, e ainda sendo mais um fato econômico que político, tende a criar certas condições de igualdade social e a fortalecer o intercâmbio 
cultural entre e dentro de seus países. Na América Latina, pelo contrário, mesmo que os países se encontrem estreitamente unidos pela línguao Brasil é uma exceção - e por longas e densas tradições, a integração econômica está fragmentando a solidariedade regional, principalmente pelas modalidades de "inserção excludente" dos grupos regionais (TLC, MERCOSUL) nos macrogrupos do Norte, do Pacífico e da Europa. As exigências de competitividade entre os grupos estão prevalecendo sobre as de cooperação e complementaridade regional, continua o autor, o que, por sua vez, traduz-se em "uma aceleração dos processos de concentração de ingresso, de redução do gasto social e deterioração da esfera pública".

É importante lembrar, dizo mesmo autor, que a preocupação maior. na Europa, é a questão das nações sem estado, essas identidades diluídas e subvalorizadas no processo de integração dos Estados Nacionais, o que se traduz no fortalecimento público de sua capacidade de produção audiovisual. Já na América Latina, a integração de sua produção audiovisual. ao sujeitar-se quase unicamente ao interesse privado, está "desativando" o reconhecimento do latino-americano num movimento crescente de neutralização e apagando os sinais de identidade nacionais e regionais.

Para Bezerra ${ }^{8}$, "as afirmações interpretativas do nacional. do regional, do grupal (aparências da aparência, representações de uma representação)" são um fato corriqueiro e recorrente (...) no cotidiano das pessoas, nas letras, nas artes". Construir arquétipos e estereótipos é uma atividade da qual se nutre o imaginário dos homens que têm razão e sensibilidade.

Não é nosso objetivo discutir aqui o conceito de identidade, para o nosso trabalho é suficiente entender, conforme nos alerta o autor, que os grupos sociais, seja na dimensão mais abrangente do tipo paísnação, seja em dimensão mais restrita. do tipo minorias. associações. ao reivindicarem uma posição de destaque no conjunto dos outros agrupamentos. sempre buscam maior visibilidade social. querem alirmar sua identidade. para conseguir o lugar almejado.

Para o mesmo autor. "o conceito de identidade opera. assim. no plano de uma estrutura macrossocial". que env olve. necessariamente. considerações no nível sociopolítico. histórico e semiótico".

A representação do idêntico - da identidade - supõe e contém em si a representação do seu contrário, do outrem - da alteridade. Um 
grupo social (ou uma nação) "se afirma idêntico a si mesmo, reconhece sua identidade. ao se confrontar com outra identidade, que se afirma na diferença: um conceito fundamental para se entender a convivência democrática". Daí a afirmação feita, anteriormente: "o cenário da integração regional latino-americana é mais bem compreendido quando colocado em contraste com o europeu". por exemplo.

Referindo-se aos meios massivos. Martín Barbero ${ }^{9}$ nos lembra, ainda, que nos tempos da modernização populista, nos anos 30-60. aproximadamente. os mesmos contribuíram para a gestação de um poderoso imaginário latino-americano feito de símbolos cinematográficos e musicais. Contudo, nos últimos anos, as indústrias culturais do cinema, rádio e televisão vivem uma situação paradoxal: "a inserção de sua produção cultural no mercado mundial está implicando na sua própria desintegração cultural", na sua perda de identidade. A presença no espaço do universo audiovisual de grandes empresas, como a mexicana Televisa e a brasileira Rede Globo, significa, na verdade, modelar a imagem desses povos em função de públicos, cada dia mais neutros, mais indiferenciados, diluindo as diferenças culturais no folclorismo e exotismo, mais barato e rentável.

Vista sob a perspectiva da comunicação, que é a mais relevante para nós. é fácil perceber que a globalização tem trazido consigo uma nova dinâmica social, que faz com que aquele otimista lema repetido há algumas décadas - "Um só povo, múltiplas vozes"-esteja sendo mudado, de fato já mudou para um outro lema - "Múltiplos povos. uma só voz" - mudança que resume as sempre estreitas relações mantidas pela comunicação com os poderes de fato.

É por tudo isso que é possível predizer, com pouca margem de erro, que o resultado da atuação de todas estas forças será um maior enriquecimento do Norte, graças ao empobrecimento do Sul. Um Sul enigmático onde a América Latina aparece como a grande incógnita, especialmente o Brasil, que representa a "grande esperança que nunca acaba de prosperar" ou como, recentemente, publicava um jornal espanhol: "O país do futuro que nunca chega". Essas manchetes refletem perfeitamente a atual situação brasileira e de toda a América Latina: no meio da especulação financeira, da crença generalizada nas virtudes do neoliberalismo e no poder quase absoluto da lei da oferta e da demanda, na crença cega na filosofia do mercado perfeito e 
globalizado, os fatos sociais, tantas vezes obstinados, mostram uma realidade bem diferente, a realidade de sempre. Países que, como o Brasil. acreditaram e apostaram na globalização como o caminho para sair de seu subdesenvolvimento, mas que. agora, no interior de uma grande crise internacional, estão percebendo que podem voltar à sua instabilidade habitual.

Toda essa subversão de valores leva ao desencanto, à desilusão e à decepção de um povo que se sente fraudado e enganado, porque não vê recompensadas as suas expectativas. Expectativas estas que se baseavam no auto-convencimento da sua potencialidade econômica. até então desaproveitada. Todos os brasileiros são conscientes das riquezas que possui seu país e, por isso, eles reconhecem e repudiam o atual modelo de desenvolvimento. Por que o Brasil não pode ser, então, uma potência do Primeiro Mundo? Uma das respostas, talvez a mais simples, é que um país, hoje em dia, não precisa possuir grandes recursos naturais para alcançar o "paraíso" do desenvolvimento - observe-se o caso do Japão - sobretudo considerando que as sete grandes indústrias do futuro, apontadas por alguns especialistas, são a microeletrônica. a biotecnologia, a ciência dos materiais, a aviação civil, as telecomunicações, a robótica e a informática.

A greta aberta entre o Norte desenvolvido e o Sul subdesenvolvido ou emergente. não é mais que o reflexo das relações de domínio de uns países sobre os outros. Transfere-se o discurso da luta de classes para a luta, entre os povos, pela sobrevivência. Nada de novo, até aí. A própria dinâmica do modelo capitalista empurra para esta guerra. caracterizada pela exploração progressiva dos recursos naturais de umas nações para favorecer a indústria de manufaturas de outras, uma política de investimentos financeiros e industriais especulativos naqueles países onde a mão-de-obra de operários é suficientemente barata para economizar os custos das empresas.

Contudo, no meio desse contexto, podemos formular duas perguntas. A primeira, qual é o papel dos meios de comunicação de massa na construção do discurso da globalização e de que maneira esse discurso reproduz os valores do sistema vigente? A segunda. qual é a função que vão desempenhar esses meios de comunicação e seus profissionais, no futuro próximo, no âmbito da revolução tecnológica que estamos vivendo, em um mundo onde dois de cada três trabalhadores estarão. muito em breve, empregados em alguma empresa

Comun. Inf., v. I, n. 2, p. 283-300, jul./dez. 1998 
de serviços relacionada, direta ou indiretamente, com o mundo das comunicações? Isso sem falar de milhões de pessoas condenadas ao desemprego.

Chegará um dia, como vaticinou, há quase quarenta anos, o economista americano Paul Samuelson, que uma pessoa instruída, qualificada e educada não achará emprego. No caso do Brasil, por exemplo, são cada vez mais evidentes as dificuldades que encontram as pessoas da classe média. suficientemente qualificadas, para entrar no mercado de trabalho. Por sua vez, o conflito do desemprego na Europa é uma realidade bem conhecida já há algum tempo e que, no caso espanhol, adquire proporções francamente dramáticas.

Respondendo à primeira pergunta, podemos afirmar que o discurso da globalização, através dos meios de comunicação de massa, desenvolve-se de forma paralela ao próprio discurso oficial da era reaganiana, que ocupou praticamente a década de 80 e que coincidiu com o auge da doutrina neoliberal. Os primeiros sintomas que evidenciaram a mudança, nos Estados Unidos, dos valores cunhados na década de 60, já apareceram no final dos anos 70. Acreditamos que o processo de mudanças dos padrões culturais e ideológicos começou a ser detectado na opinião pública a partir da transformação dos conteúdos da indústria cultural norte-americana, que de repente começou a reproduzir o discurso do novo poder que estava se instalando e que se estendeu até os nossos dias. De uma forma simplificada, podemos afirmar que foram estes os principais indicadores desse processo:

1) Uma mudança no discurso cinematográfico da indústria de Hollywood. Um cinema caracterizado, no período de 1966-78, por um certo compromisso de crítica contra o establishment, fruto, sem dúvida, da influência da então "Nova Esquerda Americana" (é bom lembrar o relativo sucesso do cinema independente americano e o próprio questionamento da história recente dos Estados Unidos, seja através da recuperação do gênero de gangsters ou através da visão crítica da guerra do Vietnam). foi substituído por outro em que a cinematografia, ao empenhar-se em voltar aos valores mais tradicionais do Americun wcty of life, afunda-se no mais puro nada da evasão. Tudo isso salpicado por novos heróis de ficção de "encefalograma plano" e conteúdo para-fascista. Rambo é um

Comun. Inf., v.1, n. 2. p. 283-300, jul./de= 1998 


\section{4}

exemplo. Não se pode esquecer que esse cinema norte-americano. conformador de estereótipos e arquétipos. ainda hoje continua exercendo uma grande influência em todo o mundo. quase que em forma de monopólio em muitos países. A indústria cinematográfica norte-americana, apesar das tentativas européias de freiar sua expansão no velho continente. continua obtendo lucrativos benefícios fora de suas fronteiras. Só na Espanha. em 1995. 88\% dos espectadores iam à sala de cinema ver fỉlmes norte-americanos e mais de $65 \%$ dos filmes exibidos naquele país foram produzidos nos Estados Unidos. Em 1997, os dez filmes mais vistos na Espanha eram produções norte-americanas.

Para melhor contextualizar o discurso cinematográfico brasileiro, são necessárias algumas contribuições de autores como Nogueira" ${ }^{10}: 0$ fechamento das salas nas pequenas cidades contribuiu para a "desaceleração do convívio social". A fruição solitária substituiu. gradativamente, as "trocas coletivas de afetos e idéias". Enquanto essas comunidades perdiam um espaço de encontro, a indústria cinematográfica se adaptava à nova conformação das relações econômicas e sociais. Se a desativação das salas trouxe prejuízos para as comunidades, o mesmo não aconteceu em relação às empresas que as abasteciam, pois aumentaram seus lucros. O Brasil saiu do $19^{\circ}$ lugar para o sétimo no ranking dos melhores mercados. Como explicar toda essa vitalidade? A resposta dada pelo autor, é que os motivos são diversos e complexos. Um deles pode ser atribuído à influência das empresas no mercado exibidor de filmes. Até aí. a história não parece ser muito diferente daquela já relatada. anteriormente. quando nos referíamos à Espanha. se não fora a participação de dois importantes atores nesse cenário: uma associação e um personagem peculiar, a quem ele chama, com muito humor. de "o amigo americano". Eis o seu relato:

\footnotetext{
No fundo do cenário, lá nos bastidores do mercado cinematográfico brasileiro, repousa aposentado o homem que consegue explicar a vitalidade. Conhecendo um pouco de Harry Stone e a Motion Picture Association (MPA), constata-se que o conceito de soberania pouco se aplica ao Brasil. Harry Stone vive no país do samba desde 1955. conheceu todos os presidentes e sempre foi 'amigo' das autoridades mais influentes. Afinal, seu trabalho era fazer 'amigos' nos centros de decisão.
}

Comun. Inf., v.I, n. 2, p. 283-300, jul./dez. 1998 
O epílogo da história é fácil descobrir. O nosso personagem, encantado com a nossa "afamada cordialidade", casou-se com uma brasileira, adora feijoada e ama o swing da música popular. E o autor continua com a sua narrativa: "O preço a pagar para se ter um "amigo americano’ é caríssimo: o desejo do colonizado é quase sempre o do colonizador".

A MPA entra em cena. A Motion Picture Association é uma entidade que congrega e defende com as armas necessárias, cuja escolha depende da resistência do inimigo (no caso do Brasil, usou uma "boa conversa"), os interesses dos grandes estúdios americanos. O mesmo autor nos diz que, para termos uma idéia da força da associação, ela representa a Parcumount, Universal. Columbica. Fox, Warner, United Artists, MGM e Turner. Essas empresas são responsáveis por mais de $90 \%$ dos filmes que os brasileiros assistem em cinema, vídeo e televisão. O lucro delas é sempre o mesmo: “o filme que passava na tela do cinema do interior migrou para a televisão".

Os interesses da MPA são os mesmos do povo americano, o que se explica facilmente: metade do lucro de um filme americano é proveniente dos mercados externos e o audiovisual é a sexta fonte de divisas em exportação dos Estados Unidos. As ações da MPA foram, no início dos anos 60, no Governo John Kennedy, muito estimuladas, revelando que aos países hegemônicos interessam "não só a força do poder econômico, mas também do poder simbólico; junto com o herói transmite-se também as ideologias" dominantes: "vende-se um "modo de ser" e, a partir daí, explora-se o "domínio do desejo". Essa convergência entre o econômico e o simbólico fez com que a MPA fosse, cada vez mais, protegida pela Casa Branca.

Retomando a mesma narrativa do autor, podemos afirmar que em vários momentos da história brasileira. deputados tentaram proteger os interesses do cinema nacional. Suas tentativas esbarraram sempre na ligura "cordial" de I larry Stone. que ao perceber que as suas "conversas" estavam sendo infrutiferas. ligava para o chefão da MPA. Jack Valenti. cue favia a última gestão junto ao governo local. Valenti sempre tinha um interlocutor "amigo". L as "crônicas" se sucedem ... () deputado Sarney lillho (lilho do ex-presidente José Sarney) passou um verdadeiro sufoco durante o governo do pai. Trabalhou para a aprovação da nacionalização do mercado cinematográfico. A lei chegou a ser aprovada. mas a retaliação foi imediata. O lobby de Stone e

C'omun. Inf.. 1.1. n. 2. p. 283-300, jul./de=. 1998 


\section{6}

Valenti junto ao congresso americano deu resultado: os congressistas de lá aprovaram uma lei que prejudicava a entrada de produtos brasileiros nos EUA. A lei que defendia o cinema brasileiro foi por água abaixo. Sarney Filho nunca mais tocou no assunto. Agora. uma novidade recente: o cinema brasileiro "quase" ganhou um Oscar. A crítica fica para depois.

2) O fenômeno da "televisão-lixo" e. em geral. da imprensa sensacionalista estendeu-se por todo o mundo como um rastilho de pólvora prestes a detonar uma explosão. Em poucas décadas, todas as expectativas de que a televisão se converteria em um meio cultural e formativo, chegando aos mais longínquos lugares. sumiram. Poucas diferenças de fundo podem ser observadas entre programações televisivas como a do "Ratinho" e. mais recentemente. do "Leão". ambas no Brasil, ou "Tómbola", na Espanha, praticamente sem discurso marcado ou revelando mediocridade. Isto para não falar da grande influência das telenovelas ou programas seriados que. em países como o Brasil. tanto contribuíram para afastar as pessoas das ruas. Uma televisão na qual o discurso mais intelectual que se pode aproveitar. respeitadas as devidas proporções. é o dos antigos intelectuais da esquerda para dizerem que a esquerda morreu. Já é conhecida no Brasil a manipulação da "Globo" para evitar que os intelectuais de esquerda apareçam na tela, ou apareçam o menor tempo possível.

Em se tratando da Europa, essa manipulação não é necessária, porque esses intelectuais não têm discurso, salvo aquele da atual social democracia. transformada em centro político. abraçando as virtudes do mercado. É muito revelador que quase $80 \%$ do tempo de programação televisiva da Espanha, por exemplo, estejam constituídos por espaços de lazer (telenovelas, séries. telefilmes, fundamentalmente norte-americanos ou produzidos e distribuídos pelas multinacionais norte-americanas como a "Warner" ou a "Disney", para citar apenas dois exemplos), ocupando a programação informativa somente 13\% e a formativa ou cultural, unicamente $8 \%$.

Ao falar do problema da "regionalização da programação" no Brasil. Nogueira" lembra que a tendência é que esta programação seja, cada vez mais, regionalizada. Acredita que o "caminho passa mais pelas TVs por assinatura do que pelas Redes de sinal aberto. como Rede Globo e SBT. No Brasil, a legislação acaba 
favorecendo a "concentração", em vez da descentralização do processo de abertura de novos canais". Se a questão agora é estabelecer um paralelo entre a "TV americana e a TV brasileira", ele nos lembra que " a indústria de televisão brasileira tem um modelo parecido com os estúdios de Hollywood dos anos 40. É centralizado e não favorece os produtores menores, chamados independentes". Como a TV americana, "cresceu dentro de indústria já montada, a cinematográfica, o seu desenvolvimento acompanhou uma verdadeira economia de mercado capitalista. No Brasil, a TV surgiu do teatro e do rádio, com estruturas profíssionais arcaicas e amadoras". A situação ficou mais complicada em razão da ingerência de um Estado militar que patrocinou as TVs por rede. com os seguintes objetivos: "ter o controle ideológico da produção; integrar o Brasil através das emissões centralizadas no eixo Rio e São Paulo". Como é possivel perceber. não é fácil comparar as duas TVs, a americana e a brasileira. Enquanto uma "opera numa economia competitiva", a outra dá agora "os primeiros sinais de descentralização", embora relativa. As TVs por assinatura também são controladas por empresas que sustentam as emissoras de sinal aberto, como a Rede Globo.

3) A ausência escandalosa, a partir dos anos 80, de referenciais intelectuais e ideológicos, de contribuições originais e inovadoras de pensamento no mercado editorial, o que contrasta com a hiperinflação de livros desse tipo que enchiam as livrarias de todo o mundo nas décadas de 60 e 70. A falta de um verdadeiro discurso da esquerda para contrapor-se ao chamado "discurso único", vem ratificando essa afirmação. As vitrines das livrarias do mundo globalizado estão cheias do "nada": "Como se fazer um milionário em um ano", "Como ser mulher e não morrer na tentativa" etc.

Com relação à segunda pergunta. sobre a função que irão desempenhar. no futuro. os meios de comunicação de massa e seus profissionais. não existe uma resposta clara. Pode-se afirmar, sim. que o desenvolvimento das novas tecnologias vai gerar novos modelos de mediação e prática protissional. o que abre incríveis possibilidades no campo da pesquisa cientílica. Pesquisas que, no nosso entender, devem estar direcionadas para a análise de qual vai ser o papel mediador dessas novas tecnologias. como vai se operar a mediação, qual vai ser

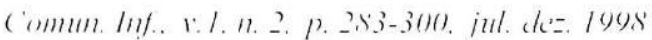




\title{
298
}

o papel receptor dos usuários dessas tecnologias e que funções vão ter em relação aos modos de pensar que. seguramente. surgirão como conseqüência do emprego desses instrumentos de comunicação.

Poderíamos concluir. citando as palavras pronunciadas. recentemente. pelo economista norte-americano J. K. Galbraith: que. no meio da atual crise econômica internacional. talvè a pior descle a Grande Depressão dos anos 30). o único tema merecedor. hoje. de grandes manchetes e acompanhamentos da imprensa internacional scja a vida sexual do Presidente Clinton. Aplicação da Agenda Sérninge?

\begin{abstract}
Globalization is analyzed in some of its various interfaces, especially emphasizing its relations with the media. It's discussed some contemporary macrotendencies of the communicative in Europe - particularly in Spain - and in Latin America, with highlight to Brazil. It 's sought, through a comparative study, to point out the new challenges imposed to research on communication in the context of the neoliberal model.
\end{abstract}

Key words: Globalization; identities; techninization of society; new medial speeches; receivers; social imaginary.

\section{Notas}

I FISKE, John. Power/ power works. New York: Pantheon Books, 1993. p.2.

2 OROZCO GOMEZ, Guillermo. "Mas-mediación” y "audiencia-cion macrotendenciaa en las sociedades latinoamericanas de fin de milenio. In: CONGRESSO BRASILEIRO DE CIÊNCIAS DA COMUNICAÇÃO, 20, SantosSP, Brasil, 1997.

3 GIROUX, Henry \& McLAREN, Peter. Betwen borders. Londres: Routtledge, 1994.p. 2.

4 OROZCO GOMEZ, op. cit., p.2.

5 No campo conceitual, não podemos confundir globalização com mundialização. Mundializar a economia significa implantar instituições políticas de âmbito mundial, capazes de re-engastar as forças econômicas, submetendo seus movimentos a regras, metas e propósitos elaborados de forma consciente e politicamente estabelecidos. Vista assim. seria o "fruto supremo do processo civilizatório". Globalização é exatamente o oposto. Ela obedece aos desejos dos grandes grupos industriais e dos detentores de vastos recursos financeiros.

Comun. Inf., v.1, n. 2, p. 283-300, jul./de=. 1998 
Seus interesses "são promovidos e ao mesmo tempo dissimulados pelo aparente funcionamento dos mecanismos impessoais do mercado" (Martins, 1996, p.56$57)$.

6 Henrique Rattner, é mestre em Sociologia e doutor em Economia Política, pela Universidade de São Paulo, é professor de Economia da Universidade de São Paulo - USP, Diretor Nacional do Programa LEAD - Brasil (Lideranças para o Meio Ambiente e Desenvolvimento Sustentado).

7 MARTIN BARBERO, Jesus. Globalización y multiculturalid: notas para una agenda de investigación. In: CONGRESSO BRASILEIRO DE CIÊNCIAS DA COMUNICAÇÃO, 20, Santos-SP, Brasil, 1997.

8 BEZERRA. Holien Gonçalves. (Universidade Federal de Goiás, Faculdade de Comunicação e Biblioteconomia, Goiânia-GO, Brasil). História e identidades: informação pessoal. 1994.

9 MARTIN BARBERO, Jesus. op.cit., p.5.

10 NOGUEIRA, Lisandro. (Universidade Federal de Goiás, Faculdade de Comunicação e Biblioteconomia, Goiânia - GO, Brasil). O amigo americano: informação pessoal. 1998.

11 Op. cit., p.8.

\section{Referências bibliográficas}

A.QUIJANO. Modernidad, identidad y utopia en América Latina. Lima: Sociedad \& Política, 1979.

BARRETO, Aldo. As novas tecnologias de informação e a geração do conhecimento. Comunicuççõo \& Informaçc̃o, Goiânia: Facomb, v.1, n.1, p.12, jan.jun. 1998.

BAUDRILLARD, J. Latranparence du mal. Paris: Galile, 1990.

CHOMSKY, Noam. Entrevista. El País. Madrid, 03 de novembro de 1998.

CISNEROS, José E. Identidad cultural e entercambio global. Ejes, circulos y redes culturales desde una cultura propria. In: MARTÍN BARBERO, Jesus (Coord.). En torno a la identidad latinoamericana. Mexico: UAM, 1992.

DIETERICH, Heinz. El muevo ordem mundial ola especie en su laberinto, VVAA: el nuevo ordem mundial o la conquista interminable. Tafalla: Txalaparta, 1991.p.169.

EUDES, Y. A colonizucion cle las conciencicss. Las centrales USA de exportación cultural. Barcelona: Gustavo Gili, 1984.

GARCIA CANCLINI, Nestor. ('ultur'us hihridas: estratégias para entrar y salir de la modernidad. Mexico: Grijalbo, 1990.

HAMELINK. Cees J. La aldea transnacional. El papel de los trusts en la comunicación mundial. Barcelona: Gustavo Gili, 1981. p.25.

MAFESOLI, M. O tempo dus trihos: o declínio do individualismo nas sociedades de massa. Trad. de M. L. Menezes. Rio de Janeiro: Forense, 1987.

MARTIN SERRANO. M. La producción social de comunicación. Madrid: Alianza, 1986. p. 15.

Comun. Inf., v.I, n. 2. p. 283-300, jul./de=. 1998 
MATTELART, Armand. La publicidad. Barcelona: Paidós, 1991.

MARTINS, Carlos Estevam. Globalizaçào e democraciar. s.n.t. p.54.

LYOTARD, Jean-François. Algo assim como: comunicação... sem comunicação. In: PARENTE. André (Org.). Imagem-mciyuina: a era das tecnologias virtuais. Rio de Janeiro: Ed. 34, 1996. p.264.

PARENTE, André (Org.). Imagem-máquincr: a era das tecnologias virtuais. Tradução por Rogério Luiz et alii. Rio de Janeiro: Ed. 34, 1996. p.7.

PROSS, Harry. Prólogo. In: MARTIN SERRANO. M. Laproducción social de comunicacion. Madrid: Alianza. 1986. p.15.

SANTOS. Milton Almeida dos. Mapa do mundo: tempo e espaços hegemônicos. In: MEDINA. Cremilda: GRECO. Milton (Org.). Saher plural: o discurso fragmentalista da ciência e a crise de paradigmas; projeto. São Paulo: USP/ECA; Brasilia: CNPq. 1994. p. 215-220. (Novo Pacto da Ciência, 3). 